\title{
PEMANFAATAN HASIL HUTAN BUKAN KAYU OLEH MASYARAKAT DESA BULUK JEGARA KECAMATAN KAYAN HILIR KABUPATEN SINTANG
}

\author{
(Utilization of Non-Timber Forest Products by Rural Communities in Buluk Jegara Villages \\ sub-district kayan hilir in Sintang Regency)
}

\author{
Abrit Guntur Setiawan, H.A. Oramahi, Hafiz Ardian \\ Fakultas Kehutanan Universitas Tanjungpura Jl. Daya Nasional, Pontianak 78124 \\ Email: abritguntur95@gmail.com
}

\begin{abstract}
This study aims to determine utilization of non-timber forest products from villages in the forest area, namely Buluk Jegara Village, Kayan Hilir District, Sintang District. The research method used was interviews with communities in Buluk Jegara Village and surveys in the Buluk Jegara village forest area. The number of respondents is 75 people. The results of research on nontimber forest products in Buluk Jegara Village showed that there were 20 types of non-timber forest products utilized by the people of Buluk Jegara Village. Types of non-timber forest products utilized by the people of Buluk Jegara Village includePerupuk (Pandanus tectorius), Senggang (Hornstedtia alliacea), Wi Segak (Calamus caesius blume), Damar(Shorea hopea), Bambu/Buluh(Dendrocalamus asper backer), Bedegak (Dicranopteris linearis), Rian (Durio zibetthinu), Engkabang (Shorea macrophylla), Purun (Lepironia articulata), Sagu (Metroxylon sagu), Nau (Arenga pinnata), Kandis (Garcinia celebica), Kemantan (Mangifera foetida), Mawang (Mangifera pajang), Bekeruk (Polypodium verrucosum), Bungkang (Syzygium polyanthum), Lemidau (Gnetum Gnemon L.), Miding (Stenochlena polustris), Lensat (Lansium domesticum), and Lengkus (Dimocarpus longan L.). The productive type of non-timber forest products which are the most dominant are utilized by the people of Buluk Jegara Village.
\end{abstract}

Keywords: Bamboo, Buluk Jegara, Non-timber forest products, Rattan.

\section{PENDAHULUAN}

Hasil hutan bukan kayu merupakan sumber daya alam yang masih banyak terdapat di Indonesia dan keberadaanya dimanfaatkan sebagai mata pencaharian oleh masyarakat. Menurut Peraturan Menteri Kehutanan Nomor P.35/ Menhut-II/ 2007 tentang Hasil Hutan Bukan Kayu dinyatakan hasil hutan bukan kayu adalah hasil hutan hayati baik nabati maupun hewani beserta produk turunan dan budidaya kecuali kayu yang berasal dari hutan berupa rotan, bambu, getah, daun, kulit, buah, dan madu dan lain-lain.
Penelitian Yudas et al (2017) menyatakan bahwa terdapat 30 jenis tanaman obat dari hutan yang digunakan masyarakat di Desa Entogong Kecamatan Kayan Hulu Kabupaten Sintang. Sementara itu, penelitian Simanjuntak et al. (2017) menyatakan masyarakat di Dusun Parit Pangeran Desa Tanjung Saleh Kecamatan Sungai Kakap Kabupaten Kubu Raya memanfaatkan hasil ikan, kepiting dan tumbuhan mangrove dari hutan mangrove yang berada di sekitar desa. Sebelumnya, Hariyanti et al. (2015) menyatakan bahwa masyarakat 
di sekitar kawasan hutan KPH Model Kapuas Hulu, khususnya yang berada di Desa Tamao Kecamatan Embaloh Hulu memanfaatkan sumber daya hutan untuk kayu konstruksi, bahan obatobatan, tanaman hias serta sebagai sumber bahan pangan.Diba et al(2017) menyatakan masyarakat didesa Nanga Betung keamatan Boyan Tanjung kabupaten Kapuas Hulu memanfaatkan hasil hutan bukan kayu tiga jenis pemanfaatan jenis HHBK konsumtif, HHBK produktif dan obat-obatan. Penelitian ini bertujuan untuk mendapatkan jenis-jenis hasil hutan bukan kayu yang dimanfaatkan oleh Masyarakat di Desa Buluk Jegara serta bagaimana cara pemanfaatannya.

\section{METODE PENELITIAN}

Penelitian dilakukan di Desa Buluk Jegara Kecamatan Kayan Hilir Kabupaten Sintang.Waktu penelitian dilaksanakan selama 2 minggu di lapangan.Metode penelitian menggunakan metode wawancara dan survey ke lokasi hutan di sekitar Desa Buluk Jegara Kecamatan Kayan Hilir Kabupaten Sintang. Data yang di kumpulkan meliputi : (1). Data primer, yaitu data yang diperoleh dengan cara mengedarkan kuisioner dan melakukan wawancara terhadap responden. Jumlah responden sebanyak 75 orang.Kriteria responden meliputiMasyarakat di DesaBulukJegara berumur minimal 17 tahunkeatasatau yang sudah berkeluarga serta berdomisili di desaBulukJegaralebihdari 5 tahun.

\section{HASIL DAN PEMBAHASAN}

Sebanyak 75 orang responden masyarakat Desa Buluk JegaraKecamatan Kayan Hilir Kabupaten Sintang diwawancarai untuk mengetahui hasil hutan bukan kayu yang di manfaatkan.Jumlah tersebut 49 (65\%) responden berjenis kelamin dan sisanya $26(35 \%)$ perempuan. Tingkat pendidikan responden di Desa buluk Jegara yaitu SD29 (38\%), SMP 19 (25\%), SMA $22(29 \%)$ dan S1 (6\%).

\section{Pemanfaatan Jenis-Jenis Hasil Hutan} Bukan Kayu

Hasil wawancara dengan masyarakat di Desa Buluk Jegara Kecamatan Kayan Hilir, Kabupaten Sintang diperoleh jenis-jenis Pemanfaatan hasil hutan bukan kayu (HHBK) seperti pada Tabel 1 berikut. 
Tabel 1. Pemanfaatan hasil hutan bukan kayu oleh masyarakat Desa Buluk Jegara Kecamatan Kayan Hilir Kabupaten Sintang Provinsi Kalimantan Barat (Utilization of non-timber forest products by the people of Buluk Jegara Village, Kayan Hilir District, Sintang Regency, West Kalimantan Province)

\begin{tabular}{|c|c|c|c|c|c|}
\hline No & $\begin{array}{l}\text { Nama } \\
\text { Lokal }\end{array}$ & $\begin{array}{l}\text { Nama } \\
\text { Indonesia }\end{array}$ & Nama Ilmiah & $\begin{array}{c}\text { Bagian } \\
\text { dimanfaatk } \\
\text { an }\end{array}$ & Kegunaan \\
\hline 1 & Perupuk & Pandan Duri & Pandanus tectorius & Daun & Bahan Kerajinan tangan \\
\hline 2 & Sengang & $\begin{array}{l}\text { Pining } \\
\text { Bawang }\end{array}$ & Hornstedtia alliacea & Pelepah & Bahan Kerajinan tangan \\
\hline 3 & $\mathrm{Wi}$ & Rotan & Calamus caesius blume & $\begin{array}{l}\text { Batang, } \\
\text { Buah }\end{array}$ & $\begin{array}{l}\text { Bahan Kerajinan tangan, } \\
\text { Konsumsi }\end{array}$ \\
\hline 4 & Damar & Damar & Shorea hopea & Getah & $\begin{array}{l}\text { Lem Perahu } \\
\text { Konsumsi, bahan }\end{array}$ \\
\hline 5 & $\begin{array}{l}\text { Pering/ } \\
\text { Buluh }\end{array}$ & Bambu & $\begin{array}{l}\text { Dendrocalamus asper } \\
\text { backer }\end{array}$ & $\begin{array}{l}\text { Batang, } \\
\text { Daun }\end{array}$ & $\begin{array}{l}\text { kerajinan tangan, bahan } \\
\text { material kandang ternak, } \\
\text { bahan perangkap ikan }\end{array}$ \\
\hline 6 & Demam & Resam & Dicranopteris linearis & Batang & Bahan Kerajinan tangan \\
\hline 7 & Rian & Durian & Durio zibetthinu & Buah & Konsumsi \\
\hline 8 & $\begin{array}{l}\text { Engkaban } \\
\mathrm{g}\end{array}$ & Tengkawang & Shorea macrophylla & $\begin{array}{l}\text { Buah, } \\
\text { Getah }\end{array}$ & $\begin{array}{l}\text { Konsumsi, lem } \\
\text { tradisional }\end{array}$ \\
\hline 9 & Purun & Purun & Lepironia articulate & Daun & Bahan kerajinan tangan \\
\hline 10 & Sagu & Sagu & Metroxylon sagu & $\begin{array}{l}\text { Batang, } \\
\text { umbut, } \\
\text { getah, daun }\end{array}$ & $\begin{array}{l}\text { Konsumsi, pakan ternak, } \\
\text { lem tradisional, atap } \\
\text { rumah/rumah lading }\end{array}$ \\
\hline 11 & $\mathrm{Nau}$ & Enau & Arenga pinnata & $\begin{array}{l}\text { Batang, } \\
\text { ijuk, buah, } \\
\text { daun }\end{array}$ & $\begin{array}{l}\text { Konsumsi, bahan } \\
\text { bangunan, bahan } \\
\text { kerajinan tangan, atap } \\
\text { rumah/rumah lading }\end{array}$ \\
\hline 12 & Kandis & Kandis & Garcinia celebica & Buah & Konsumsi \\
\hline 13 & Kemantan & Kemantan & Mangifera foetida & Buah & Konsumsi \\
\hline 14 & Mawang & Mawang & Mangifera pajang & Buah & Konsumsi \\
\hline 15 & $\begin{array}{l}\text { Pakuk } \\
\text { Pantai }\end{array}$ & Pakis & Polypodium verrucosum & Daun & Konsumsi \\
\hline 16 & Bungkang & Salam Hutan & Syzygium polyanthum & Daun & Konsumsi \\
\hline 17 & Lemidau & $\begin{array}{l}\text { Melinjo } \\
\text { Hutan }\end{array}$ & Gnetum gnemon L. & Buah, Daun & Konsumsi \\
\hline 18 & Miding & Pakis & Stenochlena polustris & Daun & Konsumsi \\
\hline 19 & Lensat & Langsat & Lansium domesticum & Buah & Konsumsi \\
\hline 20 & Lengkus & Kelengkeng & Dimocarpus longan $L$. & Buah & Konsumsi \\
\hline
\end{tabular}

Hasil hutan bukan kayu yang paling dominan dimanfaatkan oleh Masyarakat di Desa Buluk Jegara Kecamatan Kayan Hilir Kabupaten Sintang adalah jenis produksi berupa kerajinan sepertibahan perupuk, senggang, rotan, bambu, dan purun pada Tabel 2 berikut. 
Tabel 2. HHBK yang paling dominan digunakan masyarakat Desa Buluk Jegara Kecamatan Kayan Hilir Kabupaten Sintang (the most dominant nontimber forest products used by the people of Buluk Jegara Village, Kayan Hilir District, Sintang Regency)

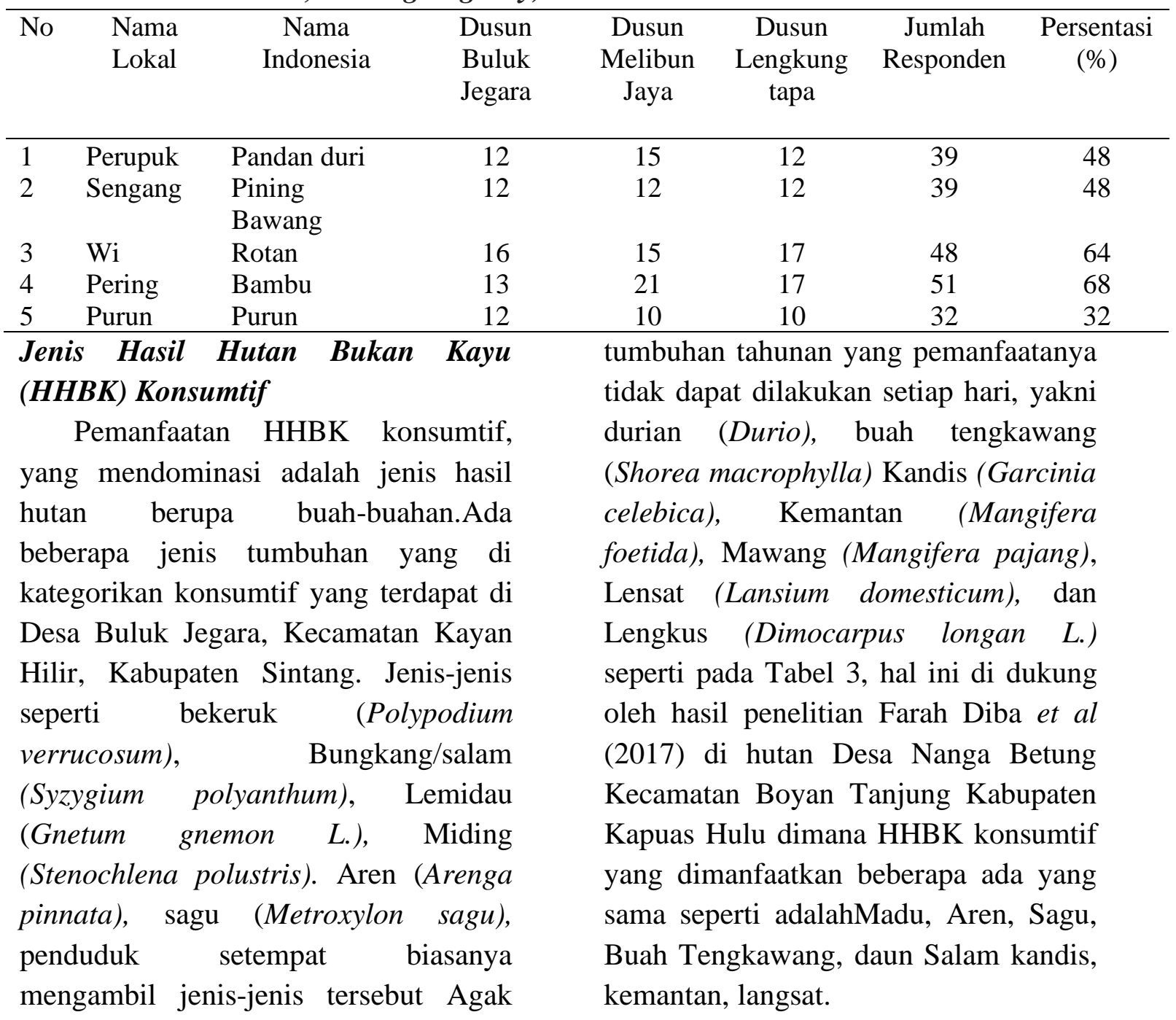

Jarang. Selain itu ada juga jenis-jenis 
Tabel 3. HHBK Konsumtif yang dimanfaatkan oleh masyarakat Desa Buluk Jegara (Consumptive non-timber forest products utilized by the people of Buluk Jegara Village)

\begin{tabular}{|c|c|c|c|c|c|}
\hline No & $\begin{array}{l}\text { Nama } \\
\text { Lokal }\end{array}$ & $\begin{array}{c}\text { Nama } \\
\text { Indonesia }\end{array}$ & Nama Ilmiah & $\begin{array}{c}\text { Bagian } \\
\text { Dimanfaatkan }\end{array}$ & Kegunaan \\
\hline 1 & Rian & Durian & $\begin{array}{l}\text { Dendrocalamus asper } \\
\text { backer }\end{array}$ & Buah & Konsumsi \\
\hline 2 & Engkabang & Tengkawang & Shorea macrophylla & Buah & Konsumsi \\
\hline 3 & Sagu & Sagu & Metroxylon sagu & Batang, umbut & Konsumsi \\
\hline 4 & $\mathrm{Nau}$ & Aren & Arenga pinnata & Batang, buah & Konsumsi \\
\hline 5 & Kandis & Kandis & Garcinia celebica & Buah & Konsumsi \\
\hline 6 & Kemantan & Kemantan & Mangifera foetida & Buah & Konsumsi \\
\hline 7 & Mawang & Mawang & Mangifera pajang & Buah, Daun & Konsumsi \\
\hline 8 & Bekeruk & Pakis & Polypodium verrucosum & Daun & Konsumsi \\
\hline 9 & Bungkang & Salam & Syzygium polyanthum & Daun & Konsumsi \\
\hline 10 & Lemidau & Melinjo & Gnetum gnemon $L$. & Buah, Daun & Konsumsi \\
\hline 11 & Miding & Pakis & Stenochlena polustris & Daun & Konsumsi \\
\hline 12 & Lensat & Langsat & Lansium domesticum & Buah & Konsumsi \\
\hline 13 & Lengkus & Lengkeng & Dimocarpus longan L. & Buah & Konsumsi \\
\hline
\end{tabular}

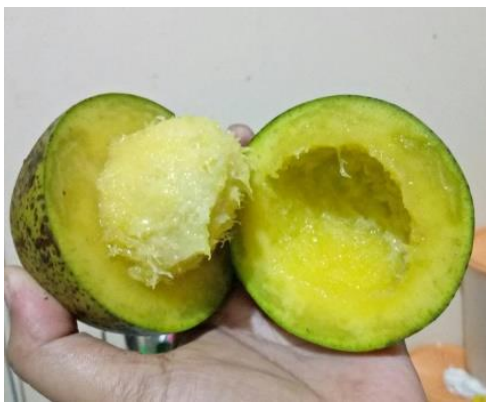

a

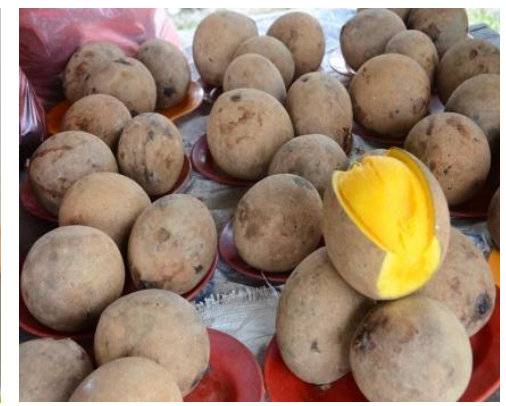

b

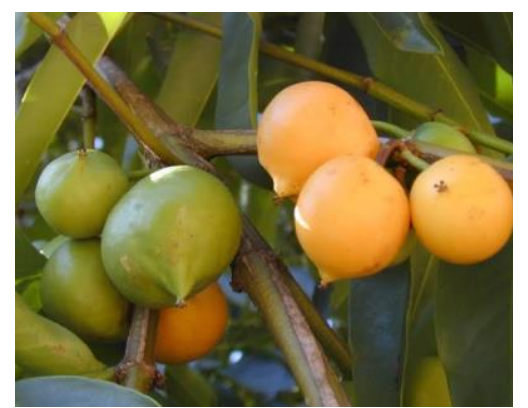

c

Gambar 1. Jenis Hasil Hutan Bukan Kayu Konsumtif: a. Kemantan; b. Mawang; c. Kandis (Types of Non-Timber Forest Products Consumptive: a. Kemantan; b. Mawang; $c$. Kandis)

\section{Hasil Hutan Bukan Kayu (HHBK) Produktif}

Dari Hasil pengamatan jenis HHBK tersebutyang dominan dimanfaatkan oleh masyarakat Desa Buluk Jegara Kecamatan Kayan Hilir Kabupaten Sintang untuk bahan baku kerajinan, hal sejalan dengan penelitian yang dilakukan oleh Nono (2017) di Desa Labian Ira'ang dan Desa Datah Diaan di Kabupaten Kapuas HuluPemanfaatan dimana HHBK yang memiliki fungsi produksi di dominasi bahan kerajinan. hasil hutan produktif yang digunakan untuk mebuat kerajinan dari HHBK dapat dilihat pada Tabel 4.Hasil hutan berupa bemban, rotan dan pandan duri umumnya digunakan untuk membuat kerajinan tangan.Produk kerajinan tangan dijual dan untuk pemakaian pribadi. 
Tabel 4.HHBK produktif yang dimanfaatkan oleh masyarakat Desa Buluk Jegara (productive non-timber forest products utilized by the people of Buluk Jegara Village)

\begin{tabular}{|c|c|c|c|c|c|}
\hline No & Nama Lokal & Nama Indonesia & Nama Ilmiah & $\begin{array}{c}\text { Bagian } \\
\text { Dimanfaatkan }\end{array}$ & Kegunaan \\
\hline 1 & Perupuk & Pandan Duri & $\begin{array}{l}\text { Pandanus } \\
\text { tectorius }\end{array}$ & Daun & Kegunaan \\
\hline 2 & Senggang & Pining Bawang & $\begin{array}{l}\text { Hornstedtia } \\
\text { alliacea }\end{array}$ & Pelepah & Kerajinan \\
\hline 3 & wi segak & Rotan & $\begin{array}{l}\text { Calamus } \\
\text { caesius blume }\end{array}$ & Batang & Kerajinan \\
\hline 4 & Pering & Bambu & $\begin{array}{l}\text { Dendrocalamus } \\
\text { asper backer }\end{array}$ & Batang & Kerajinan \\
\hline 5 & Bedegak & Resam & $\begin{array}{l}\text { Dicranopteris } \\
\text { linearis }\end{array}$ & Batang & Kerajinan \\
\hline 6 & Purun & Purun & $\begin{array}{l}\text { Lepironia } \\
\text { articulate }\end{array}$ & Daun & Kerajinan \\
\hline
\end{tabular}
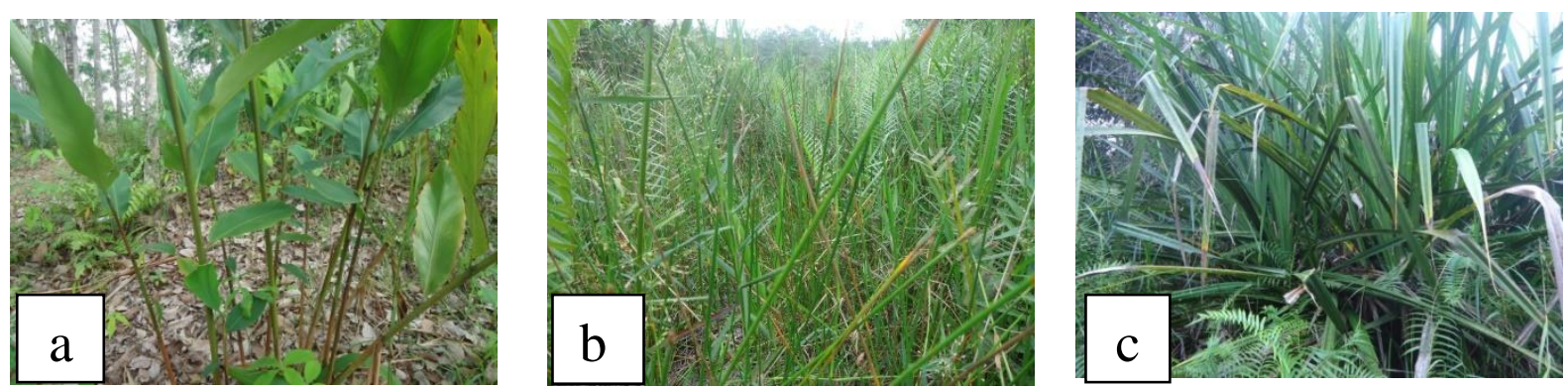

Gambar 2. Jenis HHBK Produktif : a. Pining Bawang; b. Purun; c. Pandan Duri (types of productive non-timber forest products: a. Pining Bawang; b. Purun; c. Pandan Duri )

Hasil kerajinan tangan tradisional merupakan produk yang paling sering dibuat oleh penduduk ketiga Dusun yang ada di Desa Buluk Jegara ini. Masyarakat biasanya membuat kerajinan tangan seperti bubu (perangkap ikan), Kemansai (penangkaap ikan), Ruyut, cungking, takin (wadah tempat membawa barang bawaan), tempat sampah, dan tiker yang terbuat dari rotan, mereka membuat kerajinan tersebut di sela-sela waktu istirahat atau pada saat tidak pergi ke hutan, sedangkan untuk membuat bubu biasanya kaum laki-laki membuatnya menjelang musim mencari ikan.

Nilai Ekonomi Hasil Hutan Bukan Kayu

Hasil hutan yang memiliki nilai ekonomi rata-rata adalah hasil olahan HHBK yang berupa kerajinan oleh masyarakat setempat seperti dari jenis HHBK perupuk (Pandanus tectorius), senggang (Hornstedtia alliacea, bambu (Dendrocalamus asper backer), rotan (Calamus caesiusblume), resam (Dicranopteris linearis), dan purun (Lepironia articulata). Nilai ekonomi pemanfaatan HHBK yang diperoleh dari 
responden di Desa Buluk Jegara adalah nilai dari hasil produksi HHBK seperti Hasil produksi dari Pandan duri berupa tikar dan takin.Produksi dari Pining Bawang berupa tikar, takin, cupai. Hasil Produksi dari Rotan berupa Kemansai, Ruyut, Cungking, sedangkan hasil produksi dari Bambu seperti caping, bubu, cupai, tapu laung dan hasil
Produksi dari Purun yaitu Tikar, seperti pada tabel 5,hal ini di dukung oleh penelitian Belinda Hastari dan Reri Yulianti (2018) di KPHL KapuasKahayan dimana Hasil Hutan Bukan Kayu (HHBK) bernilai ekonomi yang dimanfaatkan masyarakat dari kawasan KPHL Kapuas-Kahayan di dominasi HHBK produktif.

Tabel 5. Nilai Ekonomi Pemanfaatan Hasil Hutan Bukan Kayu oleh masyarakat Desa Buluk Jegara Kecamatan Kayan Hilir Kabupaten Sintang Provinsi Kalimantan Barat (Economic Value of Non-Timber Forest Product Utilization by the people of Buluk Jegara Village, Kayan Hilir District, Sintang Regency, West Kalimantan Province)

\begin{tabular}{|c|c|c|c|c|c|}
\hline No & $\begin{array}{l}\text { Jenis hasil } \\
\text { hutan }\end{array}$ & $\begin{array}{c}\text { Bagian yang } \\
\text { dimanfaatkan }\end{array}$ & $\begin{array}{c}\text { Persentase Nilai Per Jenis } \\
\text { berdasarkan kuesioner } \\
(\%)\end{array}$ & $\begin{array}{l}\text { Jenis Hasil } \\
\text { Produksi }\end{array}$ & $\begin{array}{l}\text { Nilai Ekonomi } \\
\text { (Rp/unit) }\end{array}$ \\
\hline \multirow[t]{2}{*}{1} & Pandan & Daun & 48 & Tikar & $100.000-250.000$ \\
\hline & Duri & & & Takin & $50.000-200.000$ \\
\hline \multirow[t]{3}{*}{2} & Pining & Pelepah & 48 & Tikar & $100.000-200.000$ \\
\hline & Bawang & & & Takin & $50.000-200.000$ \\
\hline & & & & Cupai & $50.000-150.000$ \\
\hline \multirow[t]{3}{*}{3} & Rotan & Batang & 64 & Kemansai & $100.000-300.000$ \\
\hline & & & & Ruyut/beruyut & $70.000-200.000$ \\
\hline & & & & Cungking & $150.000-300.000$ \\
\hline \multirow[t]{3}{*}{4} & Bambu & Batang & 68 & Caping & $70.000-200.000$ \\
\hline & & & & Bubu & $100.000-300.000$ \\
\hline & & & & Cupai & $70.000-300.000$ \\
\hline 5 & Purun & Daun & 42,66 & Tikar & $70.000-150.000$ \\
\hline
\end{tabular}




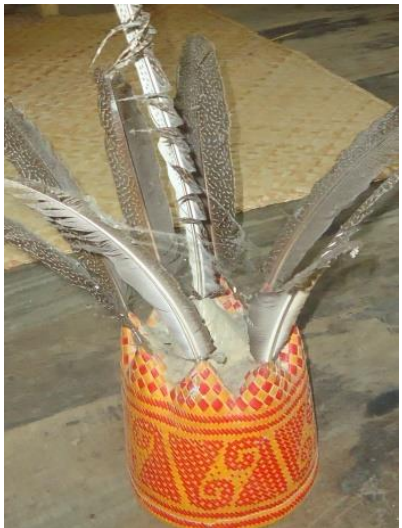

a

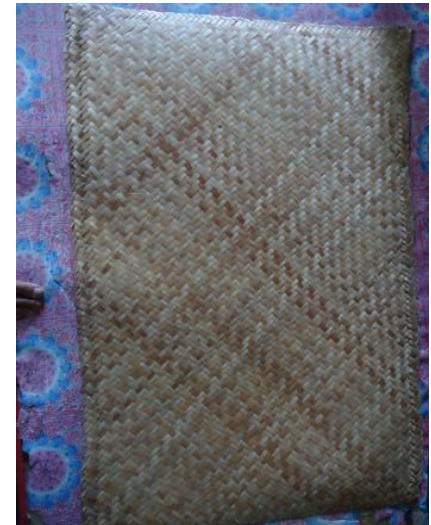

b

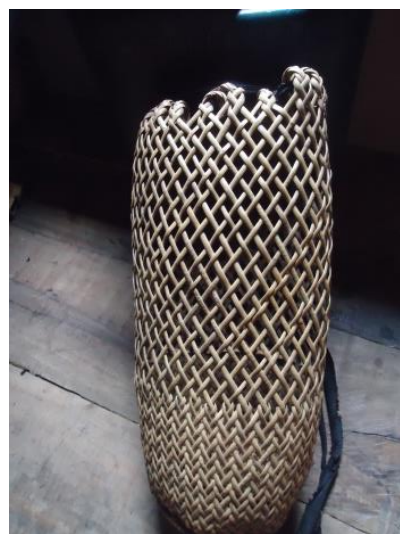

c

Gambar 3. Beberapa Bentuk Kerajinan yang Terdapat di Desa Buluk Jegara: a. Tapu Laung Dari Bambu; b. Tikar dari Pining Bawang; c. Beruyut dari Rotan. (Some Forms of Crafts Available in Buluk Jegara Village : Tapu Laung of Bamboo; b. Mat Of Pining Bawang; c. Beruyut of Rattan)

Nilai yang diperoleh dari pasar persaingan sempurna merupakan nilai baku karena memenuhi keinginan penjual dan pembeli serta memberikan surplus kesejahteraan yang maksimal (Nurfatriani, 2006), Harga pasar dari desa penelitian ini secara umum sama dikarenakan lokasi yang saling berdekatan dan pasar lokal yang digunakan untuk menjual hasil hutan juga sama.

Nilai ekonomi hasil hutan bukan kayu yang diperoleh dari responden di Desa Buluk Jegara Kecamatan Kayan Hilir Kabupaten Sintang. HHBK ini akan memiliki nilai ekonomi hanya jika ada permintaan atau pesanan saja.Produk dari pengelolaan HHBK yang paling dominan dan memiliki nilai ekonomi yang paling tinggi adalah tikar, hal ini karena tikar sangat banyak digunakan oleh masyarakat, tikar ini dapat dibuat dari beberapa macam tumbuhan seperti pandan duri, pining bawang, dan purun. Untuk membuat satu buah tikar di perlukan 1 sampai 3 hari diwaktu istirahat berkebun dan berladang, tikar memiliki nilai ekonomi yang berkisar antara Rp.100.000 sampai Rp.250.000 perbuahnya.Ditambah lagi saat mencari atau memanen pandan duri ini tidak memerlukan orang yang banyak sehingga bisa menghemat biaya.

\section{KESIMPULAN}

1. Hasil hutan bukan kayu di Desa Buluk Jegara berupa (HHBK) konsumtif (Durian, sagu, enau, kandis, kemantan, mawang, pakis, salam, melinjo, langsat, dan lengkeng), HHBK produktif (pandan duri, pining bawang, rotan, bambu, resam, dan purun.

2. Bagian tumbuhan yang dimanfaatkan sebagai produk HHBK adalah daun (pandan duri, bambu, purun,enau, pakis, sagu, bungkang), buah (rotan, durian, tengkawang, kandis, kemantan, mawang, melinjo hutan, 
langsat, kelengkeng), batang (rotan, bambu, resam, sagu, enau), dan getah (damar, tengkawang).

3. Produk hasil hutan bukan kayu yang ada di Desa Buluk Jegara berupa HHBK Produktif (tikar, ruyut, cupai, takin, kemansai, cungking, bubu, dan tanggoi), dan HHBK konsumtif (lempok, tempoyak dan minyak tengkawang).

\section{DAFTAR PUSTAKA}

Anonim. 2007. Peraturan Menteri Kehutanan No 35/Menhut II/2007: Tentang hasil hutan bukan kayu.

Diba F. 2017. Pemanfaatan produk hasil hutan bukan kayu di desa nanga betung kecamatan boyan tanjung kabupaten Kapuas hulu. prosiding seminar lignoselulosa. Cibinong, 12 September 2017

Hariyanti E. 2015. Etnobotani tumbuhan berguna oleh Masyarakat sekitar kawasan KPH model Kapuas hulu. Jurnal Hutan Lestari. 3 (3): 434 - 445.

Hastari B. \&Yulianti R. (2018). pemanfaatan dan nilai ekonomi hasil hutan bukan kayu di KPHL
Kapuas-Kahayan. Jurnal hutan tropis 6 (2) : 145 - 153

Nono, Diba F \& Fahrizal. (2017). Pemanfataan Hasil Hutan Bukan Kayu Oleh Masyarakat Di Desa Labian Ira'ang Dan Desa Datah Diaan di Kabupaten Kapuas Hulu. Jurnal Hutan Lestari. 5 (1): 76 87

Nurfatriani F. (2006). Konsep Nilai Ekonomi Total dan Metode Penilaian Sumberdaya Hutan. Bogor. Pusat Penelitian Sosial Ekonomi dan Kebijakan Kehutanan.

Simanjuntak D.R., Diba F \& Fahrizal. (2017). Sikap Masyarakat Terhadap Hutan Mangrove Di Dusun Parit Pangeran Desa Tanjuung Saleh Kecamatan Sungai Kakap Kabupaten Kubu Raya. Jurnal Hutan Lestari. 5 (1): 68- 75

Yudas, Diba F \& Fahrizal. (2017). Pemanfaatan Tumbuhan Obat Oleh Masyarakat Di Desa Entogong Kecamatan Kayan Hulu Kabupaten Sintang. Jurnal Hutan Lestari. 5 (2) : 241 - 252 